\title{
Intergenerational Relations and Subjective Well-Being among Chinese Oldest-0ld
}

\author{
Zhang Li, Cui Zhenhui \\ China University of Political Science and Law, Beijing, China \\ Email: Izhang@cupl.edu.cn
}

Received 6 April 2015; accepted 25 March 2016; published 30 March 2016

Copyright (C) 2016 by authors and Scientific Research Publishing Inc.

This work is licensed under the Creative Commons Attribution International License (CC BY). http://creativecommons.org/licenses/by/4.0/

(c) (i) Open Access

\begin{abstract}
This research examines how intergenerational relations impact subjective well-being among the elderly aged 85 and over in China. Through analyzing data from the 2011 wave of Chinese Longitudinal Healthy Longevity Survey (CLHLS), the results show that better intergenerational relations promote the elderly's positive feelings and reduce their negative feelings. The findings also suggest that the influence of intergenerational relations on Chinese oldest-old's subjective well-being varies by gender and residence. In addition, financial support from children or financial exchanges with offspring is found to decrease negative feelings of the Chinese oldest-old, but it does not improve their positive feelings. Such results emphasize that non-financial support from offspring may be more important factors than financial support in promoting the Chinese oldest-old's subjective well-being. The research draws future research attention to exploring non-financial forms of intergenerational support to promote Chinese oldest-old's subjective well-being.
\end{abstract}

\section{Keywords}

Elderly, Intergenerational Relations, Chinese Longitudinal Healthy Longevity Survey (CLHLS), Subjective Well-Being, Oldest-0ld, China

\section{Introduction}

With the trend of population aging, social scientists have paid more and more attention to issues of healthy aging. A group of studies have dealt with issues that are related particularly to improving the elderly's subjective wellbeing. Prior studies showed that receiving intergenerational support from adult children appeared to lead to better health and well-being of elderly parents (Levitt, Guacci and Weber, 1992). Intergenerational solidarity theory, sociologically-motivated gerontology research and attachment theoretical research have also been proposed to explain the positive association between intergenerational relations and the elderly parents' well-being. For instance, researchers suggested that characteristics of the relationship, including quality, relationship strain, pat- 
terns of attachment, can affect parental well-being (Levitt et al., 1992; Whitbeck, Hoyt, \& Tyler 2001; Carpenter, 2001; Cicirelli, 1993). It has been found that elderly parents that have relationship difficulties often tended to report worse well-being (Umberson, 1992). However, stronger attachment between parents and adult children usually related to less care-giving burden of adult children and better well-being of elderly parents (Circirelli 1993). Intergenerational solidarity theory further argued that intergenerational affection and normative solidarity was associated with a more positive aging experience (Roberts \& Bengston, 1990).

Some studies, however, pointed out contradictory results by showing that intergenerational support for elderly parents could be negative because it engendered feelings of dependence and loss of autonomy (Silverstein, Chen, \& Heller, 1996). Besides the explanation of losing dependence and autonomy, Merz and associates (2009) also explained the negative association from the quality of intergenerational relations. They argued that quality of the relations may be more important for elderly well-being than provision of actual support. If the relationship is in low quality, then providing support becomes more burdensome and therefore decreases the elderly parents' well-being. Thus, the results on intergenerational relations and elderly's subjective well-being based on studying the social context of Western countries appear to be equivocal.

As to Asian countries including China, the intergenerational relationship between adult children (and grandchildren) and their older parents is often described as strong emotional closeness, frequent contact, and mutual support (Ikking, van Tilburg and Knipscheer, 1999; Silverstein, Chen, \& Heller 1996; Silverstein, Parrott, \& Bengtson 1995). In terms of the correlation between intergenerational relations and elderly's subjective wellbeing, most analyses seemed to support a positive association between these two. For example, Shen and colleagues (2003) found that the Chinese elderly who received more support from offspring tended to report lower scores of loneliness. Through studying about 300 elderly in Hunan city of Changsha province, Deng and associates (2012) also found that better intergenerational relations and more social support could significantly improve the elderly's subjective well-being. Zhang and Li (2004) analyzed the 2000 wave of CLHLS dataset and pointed out that intergenerational support, especially support from sons, highly influenced the subjective wellbeing of the Chinese elderly. Thus, the impact of intergenerational relations on Chinese elderly's subjective well-being appeared to be more positive.

Even with a rich body of literature on intergenerational relations and the elderly's subjective well-being, prior research has limitations. First, most existing studies tended to examine the Chinese elderly as a whole without distinguishing their variation by gender and residence when studying the impact of intergenerational relations on elderly's subjective well-being. As we know, significant gender differences exist among older ages. There is also a huge rural and urban disparity in many aspects of social life in China. Those aspects include the way in which the two generations interact with each other, the strength of filial piety, etc. In China, urban residents generally enjoy better social security benefits, medical care, and health services as compared to their rural counterparts, which may also impact the rural and urban elderly's needs when receiving support from offspring. Meanwhile, modernization theories proposed that urbanization and industrialization decreased intergenerational co-residence and intergenerational relations. Under this assumption, urban and rural residents may have different intergenerational relations due to their different levels of and paces of urbanization. Second, prior research has seldom compared the impact of various forms (emotional, instrumental, or tangible) of intergenerational support on Chinese elderly's subjective well-being. In short, previous analyses have not answered the questions: Do male and female seniors benefit equally from the same forms of intergenerational support? Do the same forms of intergenerational relations impact rural and urban elderly’s subjective well-being in a similar manner? Furthermore, which forms of intergenerational support improve the elderly's subjective well-being to a greater extent?

This research intends to fill the voids of prior literature by examining how intergenerational relations impact the Chinese elderly's subjective well-being by gender and residence. In addition, the study compares how various forms of intergenerational support lead to different subjective well-being outcomes among subgroups of the Chinese elderly. Given that the elderly covers a large span of age groups and there is a considerable variation among age groups, this current research mainly focuses on studying Chinese elderly aged 85 and above. Data are derived from the newly released 2011 wave of Chinese Longitudinal Healthy Longevity Survey (CLHLS). I now turn to the introduction of data, measures and methods of the research.

\section{Data, Measures and Methods}

\subsection{Data}

This research uses newly released 2011 wave of the Chinese Longitudinal Healthy Longevity Survey (CLHLS) 
to conduct the analysis. The CLHLS data were collected by Peking University's Center for Healthy Aging and Family Studies and the China National Research Center on Aging, with support from the U.S. National Institute on Aging.

The 2011-2012 CLHLS wave was undertaken in more than 800 randomly selected counties and cities of the 23 provinces in China (Liaoning, Jilin, Heilongjiang, Hebei, Beijing, Tianjin, Shanxi, Shaanxi, Shanghai, Jiangsu, Zhejiang, Anhui, Fujian, Jiangxi, Shandong, Henan, Hubei, Hunan, Guangdong, Guangxi, Sichuan, Chongqing and Hainan). The survey covers roughly half the counties and cities of those provinces and the sample areas represent $85 \%$ of the total population of China. In the 2011-2012 survey, 3802 males and 4603 females (for a total of 8405) surveyed in 2008 were reviewed. Also, 801 males and 982 females (for a total of 1783) were newly added interviewees. Thus, the 2011 wave included 4603 males and 5585 females in the survey. This research excludes those under 85 years of age, which yields a total number of studied elderly as 5205 (3246 females and 1959 males), ranging from 85 to 114 years old with an average age of 94 .

\subsection{Measures}

\subsubsection{Measuring Intergenerational Relations}

The CLHLS had a number of questions that can be used to measure the elderly's intergenerational relations. The first question asked: 1) What is your main source of financial support? The answers included retirement wages, spouse, children, grandchildren, other relatives, local government or community, work by self, and others. This research considers this question as an important measure of financial support of the elderly from their offspring. The analysis codes main financial source coming from children or grandchildren as " 1 " and "0" if otherwise. In addition to the above question, the CLHLS questionnaire also asked the elderly: 2) How much did you receive from your son(s) or daughter(s)-in-law or daughter(s) or son(s)-in-law or grandchildren last year? Meanwhile, there were also questions asked 3) How much did you give to your son(s) or daughter(s)-in-law or daughter(s) or son(s)-in-law or grandchildren last year? I consider the questions as measures of financial exchanges between elderly and their offspring. The analysis adds all money receiving from son(s), daughter(s)-in-law, daughter(s), son(s)-in-law and grandchildren as money received from offspring. Accordingly, the research adds all money giving to son(s), daughter(s)-in-law, daughter(s), son(s)-in-law and grandchildren as money gave to offspring. For these two variables, the analysis then recodes the values as follows: 0/9999 yuan $=1,10,000 / 19,999$ yuan $=$ $2,20,000 / 29,999$ yuan $=3$ 30,000/39,999 yuan $=4,40,000 / 49,999$ yuan $=5$ and 50,000 yuan and above $=6$.

Beyond the questions asking financial support/exchange between elderly and the offspring, the CLHLS also had questions asking interactions between the elderly and their children/grandchildren in other aspects. For instance: 1) Whom do you talk to frequently in daily life? 2) To who do you usually ask for help when you have problems or difficulties? 3) Who is the first person that you talk to when you need to share your thoughts? 4) Who took care of you when you are sick? The choices for answering the questions included: spouse, son, daughter, daughter-in-law, son-in-law, grandchildren and their spouses, other relatives, friends/neighbors, social workers, nanny and nobody. The respondent was asked to choose three from the above options. Based on the four questions, the research generates four variables to represent the intergenerational relations between the elderly and their children/grandchildren, which are named as "chatting with children", "asking help from children", "sharing thoughts with children" and "taken care by children." If the respondent's answers include "children" or "grandchildren", then the four intergenerational variables are coded as " 1 ", and " 0 " if otherwise. The respondents who did not have children are coded as missing in the intergenerational relation index.

\subsubsection{Measuring Subjective Well-Being}

The Chinese elderly's subjective well-being is measured by a series of CLHLS questions evaluating the elderly's life. Those questions are: 1) How do you rate your life at present? 2) Do you always look on the bright side of things? 3) Are you happy now as when you were younger? 4) Do you often feel fearful or anxious? 5) Do you often fell lonely and isolated? 6) Do you feel the older you get the more useless you are? 7) Have you felt sad, blue, or depressed for two weeks or more in last 12 months? 8) Have you lost interest in most things, like hobbies, work, or similar activities? The responses range from 1 to 5 . "1" represents always or very good; "5" represents never or very bad. The items are recoded so that " 1 " indicates the weakest feel and " 5 " the strongest feel. Although CLHLS data were not collected to examine the psychological well-being of the elderly, the above question may not be perfect indicators of one's subjective well-being. However, Chen and Short (2008: p. 1388) 
also pointed out that: "they represent important dimensions of subjective well-being, such as life satisfaction, happiness, and loneness.” Thus, the research considers measures associated with the above questions as legitimate indicators of the elderly's subjective well-being.

Following Chen and Short (2008)'s strategy of constructing indices of subjective well-being, the analysis generates three indices by adding items 1 to 3 as an index representing positive well-being, adding items 4 to 6 as first index of negative well-being, and adding item 7 to 8 as second index of negative well-being. The above questions are considered as independent to each other. Thus, the indices are created by adding the raw scores of all variables in each set and are summary scores for each set of variables discussed above. The logic of constructing the above indices is that each group of variables measures the same concept. This strategy reduces the number of variables in the analysis and improves the efficiency of the regression models that estimate the relationship between intergenerational relations and elderly’s subjective well-being.

After summing each set of variables to a single variable, Cronbach's (1951) alpha is further used to assess the reliability of a given set of variables. The set of items is often referred to as a scale. The reliability alpha (Cronbach's alpha) is defined as the square of the correlation between the measured scale and the underlying factor. It we think of a test as "being composed of a random sample of items from a hypothetical domain of items designed to measure the same thing, alpha represents the expected correlation of one test with an alternative form containing the same number of items”(StataCorp LP 2007). The internal consistency coefficients for the three indices are alpha $=0.51,0.63,0.72$, respectively. The first two alpha values seem to be lower than the alpha value used in other research. But since only three items are used to construct the indices and the alpha value is positively related to number of items used, the alpha values are considered as acceptable. The Appendix specifies the alpha values and the items which are used to compose variables used in the analysis.

\subsubsection{Control Variables}

In additional to the above measures, a number of variables are also controlled. These variables include the elderly's demographic characteristics, such as age (which is measured in chronological years), gender, marital status (widowed, never married, divorced/separated), residence and ethnicity (Han vs. Non-Han). The elderly’s socioeconomic status (measured by education and family income prior to the survey year) is also controlled. In addition, whether the elderly's spouse died in the past three/four years (after 2008 survey) is also controlled since it has been found to be significantly related to one's subjective well-being (Chen \& Short, 2008). The research also controls for the elderly's living arrangements, health status and ADL disabilities. Health status is measured by self-rated health (SRH) in a 5-point scale (5 = very good, $4=$ good, $3=$ so so, $2=$ poor and $1=$ very poor) and ADL (activity of daily living) disabilities. ADL disability is defined as whether the respondent had limitations in activities of daily living (ADL) at the 2011 wave. ADL is measured by six items (bathing, dressing, using the toilet, indoor transferring, eating, and controlling bladder and bowel movement). Being incapable to perform any of the six activities independently is considered as having ADL disabilities. In this research, the ADL variable is coded as a categorical variable $(1=$ yes, $0=$ no $)$.

\subsection{Methods}

This research applies descriptive analysis strategy and ordinary least square (OLS) regression to examine how intergenerational relations are linked to the Chinese elderly's subjective well-being. Regression coefficients are reported here but tables with standard errors are available upon request.

\section{Results}

\subsection{Description of the Sample}

The descriptive results of the independent and control variables are shown in Table 1 . The subjective well-being variables show variations by residence and gender. On average, males and urban residents show slightly better subjective well-being scores than their female and rural counterparts. Accordingly, females and rural seniors demonstrate higher negative well-being scores (for instance, for the first negative subjective being index, the scores are 7.1 vs. 6.6 \& 7.1 vs. 6.8). The results suggest that males and urban residents are perhaps better off regarding their subjective well-being.

As to intergenerational relations, about $71.0 \%$ of the oldest-old respondents reported that their main financial 
Table 1. Descriptive analysis of independent and control variables for elderly aged 85 and over: China, 2011-2012.

\begin{tabular}{|c|c|c|c|c|c|}
\hline \multirow{2}{*}{ Variables } & \multirow{2}{*}{ Total } & \multicolumn{2}{|c|}{ Sex } & \multicolumn{2}{|c|}{ Residence } \\
\hline & & Male & Female & Urban & Rural \\
\hline \multicolumn{6}{|l|}{ Subjective well-being variables (mean) } \\
\hline 1) Positive well-being & 11.1 & 11.2 & 11.0 & 11.3 & 10.9 \\
\hline 2) Negative well-being I & 7.0 & 6.6 & 7.1 & 6.8 & 7.1 \\
\hline 3) Negative well-being II & 0.22 & 0.19 & 0.23 & 0.22 & 0.21 \\
\hline \multicolumn{6}{|l|}{ Intergenerational relation variables } \\
\hline \multicolumn{6}{|c|}{ 1) Main source of financial support from children } \\
\hline 1 = yes & 71.0 & 59.3 & 78.1 & 61.5 & 79.4 \\
\hline $0=$ no & 29.0 & 54.4 & 21.9 & 38.5 & 20.6 \\
\hline 2) Give money to children (mean) & 393.8 & 585.5 & 276.9 & 601.4 & 203.4 \\
\hline 3) Receive money from children (mean) & 2374.2 & 2394.1 & 2362.1 & 2642.9 & 2132.8 \\
\hline \multicolumn{6}{|l|}{ 4) Usually talk to children } \\
\hline 1 = yes & 61.3 & 48.5 & 69.3 & 60.1 & 62.5 \\
\hline $0=$ no & 48.7 & 51.5 & 30.7 & 39.9 & 31.5 \\
\hline \multicolumn{6}{|l|}{ 5) Share thoughts with children } \\
\hline 1 = yes & 73.2 & 60.4 & 81.2 & 71.8 & 74.4 \\
\hline $0=$ no & 26.8 & 39.6 & 18.8 & 28.2 & 25.6 \\
\hline \multicolumn{6}{|l|}{ 6) Taken care by children when sick } \\
\hline 1 = yes & 83.6 & 74.1 & 89.4 & 81.1 & 85.8 \\
\hline $0=$ no & 16.4 & 25.9 & 10.6 & 18.9 & 14.2 \\
\hline \multicolumn{6}{|l|}{ 7) Ask help from children } \\
\hline 1 = yes & 83.7 & 75.5 & 89.9 & 82.4 & 84.9 \\
\hline $0=$ no & 16.3 & 24.5 & 11.1 & 17.6 & 15.1 \\
\hline \multicolumn{6}{|l|}{ Control variables } \\
\hline \multicolumn{6}{|l|}{ 1) Currently married (\%) } \\
\hline 1 = yes & 17.3 & 34.6 & 6.8 & 18.3 & 16.3 \\
\hline $0=$ no & 82.7 & 65.4 & 93.2 & 81.7 & 83.7 \\
\hline \multicolumn{6}{|l|}{ 2) Minority (\%) } \\
\hline $1=$ yes & 6.0 & 5.5 & 6.3 & 5.0 & 7.0 \\
\hline $0=$ no & 94.0 & 94.5 & 93.7 & 95.0 & 93.0 \\
\hline \multicolumn{6}{|l|}{ 3) Sex (\%) } \\
\hline 1 = Male & 37.6 & - & - & 40.9 & 34.7 \\
\hline $0=$ Female & 62.4 & - & - & 59.1 & 65.3 \\
\hline \multicolumn{6}{|l|}{ 4) Urban (\%) } \\
\hline 1 = yes & 47.1 & 51.3 & 44.6 & - & - \\
\hline $0=$ no & 52.9 & 48.7 & 55.4 & - & - \\
\hline 5) Age & 94.8 & 92.8 & 96.0 & 95.0 & 94.5 \\
\hline 6) Self-rated health & 3.4 & 3.4 & 3.3 & 3.4 & 3.3 \\
\hline \multicolumn{6}{|l|}{ 7) ADL (\%) disabilities } \\
\hline $1=$ yes & 41.4 & 33.8 & 54.0 & 45.5 & 37.8 \\
\hline $0=$ no & 58.6 & 66.2 & 46.0 & 54.5 & 62.2 \\
\hline 8) Household income of last year & 25,342 & 27,988 & 23,772 & 31,821 & 19,855 \\
\hline 9) Education & 1.4 & 3.0 & .49 & 1.9 & 1.1 \\
\hline \multicolumn{6}{|l|}{ 10) If spouse died in past 3 years } \\
\hline 1 = yes & 12.1 & 12.9 & 11.6 & 11.8 & 12.6 \\
\hline $0=$ no & 87.9 & 87.1 & 88.4 & 88.2 & 87.4 \\
\hline \multicolumn{6}{|l|}{ 11) Living with others } \\
\hline 1 = yes & 80.3 & 80.9 & 80.0 & 80.8 & 79.0 \\
\hline $0=$ no & 19.7 & 19.1 & 20.0 & 19.2 & 21.0 \\
\hline
\end{tabular}

Source: CLHLS wave 2011. N = 5205. 
sources came from their children or grandchildren. This percentage is especially higher for females and rural seniors as compared to their male and urban counterparts (78.1\% vs. 59.3\%; 79.4\% vs. 68.5\%). This result suggests that females and rural seniors are more likely to be financial dependent on their adult children. When it comes to the financial exchange variables, the results show that, on average, the Chinese oldest-old gave 398.3 yuan to their children or grandchildren with a standard deviation of 3239.2, suggesting a substantial variation among samples. Similarly, males and urban residents reported giving more money to children or grandchildren than females and rural seniors (585.5 vs. 276.9 yuan; 601.4 vs. 203.4 yuan). As to money received from children or grandchildren, the results show that the Chinese oldest-old generally received much more money from their offspring than the amount that they gave (2374.2 vs. 398.3). Interestingly, there is no substantial differentiation between male and female seniors when it comes to the amount of money the elderly received from their offspring. Urban residents received a slightly greater amount of money from their children or grandchildren than their rural counterparts.

When the rest of the four intergenerational relation variables are considered, some interesting findings emerge here. About $61.3 \%$ of the Chinese oldest-old claimed that they usually talked to their children or grandchildren. Females tended to be more likely to chat with children than males. There is a slightly higher percentage of rural residents than urban residents that claimed often chatting with children/grandchildren. As compared to the "usually chatting with children” variable, a higher percentage of the Chinese elderly reported that often shared thoughts with their children or grandchildren (73.2\% vs. 61.3\%). Similarly, a higher percentage of females than males (81.2\% vs. 60.4\%) tended to share thoughts with children. And such a percentage is also a bit higher for rural than for urban elderly. For the next measure of intergenerational relations, whether the elderly was taken care of by children/grandchildren when they were sick, the results show that overall, 83.6\% of the respondents claimed "yes." Such a percentage is especially higher for females than for males (89.4\% vs. 74.1\%). Rural residents also reported a slightly higher percentage in this regard as compared to their urban counterparts (85.8\% vs. 81.1\%). Considering the last intergenerational relation variable, "whether asking for help from children/grandchildren when having difficulties”, the results show that, in general, 83.7\% of the respondents tended to ask for help from their children/grandchildren. And females and rural seniors seemed to be more likely to seek help from children.

In sum, the general patterns for the Chinese oldest-old's intergenerational relationship can be described as: 1) they were more likely to be "receivers" than "givers" when it comes to financial exchange between generations. 2) The Chinese oldest-old tended to receive more physical care and help from children/grandchildren when they were sick or had difficulties than receiving emotional support from offspring. 3) Meanwhile, the descriptive results also suggest that rural-urban and gender differences exist among all intergenerational relation variables studied in this research. Given such differentiations, it is necessary to disentangle the link between intergenerational relations and the Chinese elderly's subjective well-being by breaking down the elderly into subgroups by gender and residence.

Beyond the main independent variables, variations by gender and residence are also observed when the control variables that are considered. As to marital status of the respondents, males reported a much higher percentage of being married than females (34.6\% vs. 6.8\%). The marital rate is a bit higher for urban than for rural seniors (18.3\% vs. 16.3\%). There are slightly higher percentages of female and rural ethnic minorities that were selected in the sample. There are a slightly higher percentage of sample living in urban areas than rural areas (52.7\% vs. $47.3 \%)$. There are also more females who were interviewed in the survey than males (62.4\% vs. $37.6 \%)$. When it comes to the health status of the elderly, the average self-rated health (SRH) of the elderly is 3.3, meaning on average, the sampled Chinese elderly self-rated their health status as anywhere between "so-so" to "good." Males and urban seniors reported higher SRH scores than females and rural seniors. There are higher percentages of females (54.0\%) and rural residents (45.5\%) reported having ADL disabilities. The socioeconomic status of the subgroups differs considerably. The urban elderly reported an average household income prior to the survey year as 31,821 RMB, which is the highest among all subgroups. In contrast, their rural counterparts only reported an average household income in the same year as 19,855 RMB. As to educational attainments, males and urban residents claimed a greater number of years of schooling. Overall, 12.1\% of the respondents reported having spouses died since the survey year of 2008. Males and rural elderly reported higher percentages of spouse's death. About $80 \%$ of the sample reported living with other family members in the survey year. After showing the differentiation among subgroups by gender and especially by urban and rural residence, the paper now turns to a discussion of the regression results on the elderly's subjective well-being by intergene- 
rational relations.

\subsection{Regression Results}

Tables 2-4 provide the OLS regression coefficients on positive and negative well-being, respectively. The regression models examine how intergenerational relation variables influence subjective well-being of the Chinese oldest-old. Findings show that after controlling for age, sex, marital status, ethnicity, urban residence, ADL disabilities, household income, SRH, living arrangements and whether spouse died in past three years, financial exchange/support from children/grandchildren only show significant effects on negative well-being but not on positive well-being. For example, according to Table 4, main financial support from children/grandchildren reduces negative feelings of the oldest-old by $7 \%$. Table 3 also shows that both receiving money and giving money to children/grandchildren reduces negative feelings of the elderly. Specifically, for every one unit increase in offering money or receiving money, the elderly's negative feelings decrease by about $20 \%$. But males are an exception. Table 3 indicates that for males, main financial support coming from children/grandchildren increases the negative feelings of males by $32 \%$, holding other variables constant.

Table 2. OLS regression on Chinese elderly's positive well-being: Chinese aged 85 and over, 2011-12.

\begin{tabular}{|c|c|c|c|c|c|}
\hline \multirow{3}{*}{ Variables } & \multirow{3}{*}{$\begin{array}{c}\text { All } \\
\text { Model } 1\end{array}$} & \multicolumn{2}{|c|}{ Sex } & \multicolumn{2}{|c|}{ Residence } \\
\hline & & Male & Female & Urban & Rural \\
\hline & & Model 2 & Model 3 & Model 4 & Model 5 \\
\hline \multicolumn{6}{|l|}{ Intergenerational Relation Variables } \\
\hline 1) Main source of financial support from children & -0.10 & -0.15 & -0.06 & -0.17 & 0.02 \\
\hline 2) Give money to children (mean) & 0.06 & 0.20 & -0.05 & 0.08 & -0.17 \\
\hline 3) Receive money from children (mean) & 0.04 & -0.10 & 0.12 & 0.19 & -0.02 \\
\hline 4) Usually talk to children & $-0.36^{* * *}$ & $-0.52^{* * *}$ & $-0.24^{*}$ & $-0.39^{* * *}$ & $-0.35^{* *}$ \\
\hline 5) Share thoughts with children & $0.53^{* * *}$ & $0.54^{* * *}$ & $0.56^{* * *}$ & $0.34^{*}$ & $0.75^{* * *}$ \\
\hline 6) Taken care by children when sick & 0.11 & 0.17 & 0.03 & 0.06 & 0.17 \\
\hline 7) Ask help from children & -0.06 & 0.03 & -0.31 & 0.04 & -0.19 \\
\hline \multicolumn{6}{|l|}{ Control variables } \\
\hline 1) Currently married & 0.11 & 0.20 & -0.14 & 0.20 & -0.03 \\
\hline 2) Minority & -0.09 & 0.27 & $-0.35^{*}$ & 0.28 & -0.29 \\
\hline 3) Male & -0.04 & - & - & -0.07 & -0.01 \\
\hline 4) Urban & $0.25^{* * *}$ & $0.27^{* *}$ & $0.23^{* *}$ & - & - \\
\hline 5) Age & $0.01^{* *}$ & 0.01 & $0.01^{*}$ & $0.03^{* * * *}$ & -0.01 \\
\hline 6) Household income & $0.12^{* * *}$ & $0.13^{* * *}$ & $0.12^{* * *}$ & $0.14^{* * *}$ & $0.09^{* * *}$ \\
\hline 7) Education & $0.03^{* *}$ & $0.04^{* * * *}$ & 0.01 & $0.03^{*}$ & 0.03 \\
\hline 8) Self-rated health & $0.98^{* * * *}$ & $0.94^{* * * *}$ & $10.02^{* * *}$ & $0.92^{* * * *}$ & $10.08^{* * *}$ \\
\hline 9) ADL disabilities & $-0.06^{* *}$ & -0.06 & $-0.07^{* *}$ & $-0.08^{* *}$ & -0.03 \\
\hline 10) Spouse dead, $\leq 3$ years & 0.06 & -0.01 & 0.14 & 0.18 & -0.07 \\
\hline 11) Living with others & 0.07 & -0.15 & $0.24^{* *}$ & 0.21 & -0.07 \\
\hline Constant & $5.60^{* * *}$ & $5.75^{* * *}$ & $5.59^{* * * *}$ & $4.71^{* * *}$ & $7.12^{* * * *}$ \\
\hline $\mathrm{N}$ & 2381 & 1002 & 1379 & 1333 & 1048 \\
\hline Adjusted R2 & 0.26 & 0.25 & 0.26 & 0.25 & 0.25 \\
\hline
\end{tabular}

Source: see Table $1 .^{*}<0.1,{ }^{* *}<0.05,{ }^{* * *}<0.01$. 
Table 3. OLS regression on Chinese elderly’s negative well-being I: Chinese aged 85 and over, 2011-12.

\begin{tabular}{|c|c|c|c|c|c|}
\hline \multirow{3}{*}{ Variables } & \multirow{3}{*}{$\begin{array}{c}\text { All } \\
\text { Model } 1\end{array}$} & \multicolumn{2}{|c|}{ Sex } & \multicolumn{2}{|c|}{ Residence } \\
\hline & & Male & Female & Urban & Rural \\
\hline & & Model 2 & Model 3 & Model 4 & Model 5 \\
\hline \multicolumn{6}{|l|}{ Intergenerational Relation Variables } \\
\hline 1) Main source of financial support from children & 0.10 & $0.32^{* *}$ & -0.12 & 0.20 & -0.05 \\
\hline 2) Give money to children (mean) & $-0.21^{* *}$ & 0.09 & 0.38 & 0.23 & -0.08 \\
\hline 3) Receive money from children (mean) & $-0.20^{* *}$ & 0.06 & $-0.26^{*}$ & -0.15 & -0.10 \\
\hline 4) Usually talk to children & $0.28^{* * *}$ & 0.22 & 0.25 & $0.35^{* *}$ & 0.18 \\
\hline 5) Share thoughts with children & $-0.40^{* * *}$ & -0.30 & $-0.59^{* * *}$ & -0.26 & $-0.72^{* * *}$ \\
\hline 6) Taken care by children when sick & -0.11 & -0.12 & 0.26 & -0.01 & 0.11 \\
\hline 7) Ask help from children & 0.11 & -0.06 & 0.12 & -0.22 & 0.27 \\
\hline \multicolumn{6}{|l|}{ Control variables } \\
\hline 1) Currently married & $-0.50^{* * *}$ & $-0.37^{* *}$ & -0.37 & $-0.58^{* * *}$ & -0.20 \\
\hline 2) Minority & $0.28^{* *}$ & -0.22 & $0.39^{*}$ & -0.22 & 0.32 \\
\hline 3) Male & -0.84 & - & - & -0.20 & -0.18 \\
\hline 4) Urban & $-0.14^{* *}$ & $-0.27^{* *}$ & -0.16 & - & - \\
\hline 5) Age & 0.01 & -0.01 & $-0.03^{* * *}$ & $-0.02^{* *}$ & $-0.02^{* *}$ \\
\hline 6) Household income & $-0.11^{* * *}$ & $-0.12^{* * *}$ & $-0.10^{* * *}$ & $-0.14^{* * *}$ & $-0.08^{* *}$ \\
\hline 7) Education & $-0.04^{* * *}$ & -0.01 & -0.01 & -0.01 & -0.01 \\
\hline 8) Self-rated health & $-0.78^{* * *}$ & $-0.69^{* * *}$ & $-0.84^{* * *}$ & $-0.66^{* * *}$ & $-0.94^{* * *}$ \\
\hline 9) ADL disabilities & $0.19^{* * *}$ & $0.16^{* * *}$ & $0.20^{* * *}$ & $0.17^{* * *}$ & $0.18^{* * * *}$ \\
\hline 10) Spouse dead, $\leq 3$ years & 0.12 & 0.25 & -0.14 & 0.02 & -0.01 \\
\hline 11) Living with others & $-0.32^{* * *}$ & -0.06 & -0.23 & -0.20 & -0.07 \\
\hline Constant & $10.50^{* * *}$ & $10.67^{* * *}$ & $13.07^{* * *}$ & $11.88^{* * *}$ & $13.02^{* * *}$ \\
\hline $\mathrm{N}$ & 2416 & 1025 & 1391 & 1346 & 1070 \\
\hline Adjusted R2 & 0.19 & 0.15 & 0.18 & 0.16 & 0.19 \\
\hline
\end{tabular}

Source: see Table $1 .{ }^{*}<0.1,{ }^{* *}<0.05,{ }^{* * *}<0.01$.

Table 4. OLS regression on Chinese elderly’s negative well-being II: Chinese aged 85 and over, 2011-12.

\begin{tabular}{|c|c|c|c|c|c|}
\hline \multirow{3}{*}{ Variables } & \multirow{3}{*}{$\begin{array}{c}\text { All } \\
\text { Model } 1\end{array}$} & \multicolumn{2}{|c|}{ Sex } & \multicolumn{2}{|c|}{ Residence } \\
\hline & & Male & Female & Urban & Rural \\
\hline & & Model 2 & Model 3 & Model 4 & Model 5 \\
\hline \multicolumn{6}{|l|}{ Intergenerational Relation Variables } \\
\hline 1) Main source of financial support from children & $-0.07^{* * *}$ & -0.02 & -0.07 & -0.04 & -0.06 \\
\hline 2) Give money to children (mean) & -0.02 & -0.02 & -0.05 & -0.02 & 0.14 \\
\hline 3) Receive money from children (mean) & -0.03 & -0.01 & -0.01 & -0.01 & 0.01 \\
\hline 4) Usually talk to children & 0.02 & -0.01 & 0.04 & 0.02 & 0.03 \\
\hline 5) Share thoughts with children & -0.06 & -0.03 & $-0.14^{* *}$ & -0.06 & $-0.13^{*}$ \\
\hline 6) Taken care by children when sick & -0.01 & 0.3 & -0.02 & 0.03 & -0.01 \\
\hline 7) Ask help from children & 0.03 & 0.2 & 0.04 & -0.02 & 0.08 \\
\hline
\end{tabular}




\section{Continued}

\begin{tabular}{|c|c|c|c|c|c|}
\hline \multicolumn{6}{|l|}{ Control variables } \\
\hline 1) Currently married & $-0.08^{* * *}$ & -0.01 & $-0.15^{* *}$ & $-0.12^{*}$ & -0.01 \\
\hline 2) Minority & -0.04 & -0.10 & 0.04 & -0.03 & -0.02 \\
\hline 3) Male & -0.03 & - & - & -.05 & .03 \\
\hline 4) Urban & $-0.04^{* *}$ & $-0.11^{* * *}$ & 0.01 & - & - \\
\hline 5) Age & $-0.01^{* * *}$ & 0.01 & $-0.01^{* *}$ & -0.01 & $-0.01^{* *}$ \\
\hline 6) Household income & $-0.01^{* *}$ & -0.01 & $-0.02^{* *}$ & $-0.02^{* *}$ & -0.01 \\
\hline 7) Education & $-0.01^{*}$ & 0.01 & 0.01 & 0.01 & -0.01 \\
\hline 8) Self-rated health & $-0.16^{* * *}$ & $-0.09^{* * *}$ & $-0.15^{* * *}$ & $-0.12^{* * *}$ & $-0.14^{* * *}$ \\
\hline 9) ADL disabilities & $0.04^{* * *}$ & 0.02 & $0.04^{* * *}$ & $0.03^{* * *}$ & $0.03^{*}$ \\
\hline 10) Spouse dead, $\leq 3$ years & 0.03 & -0.05 & -0.02 & -0.03 & -0.06 \\
\hline 11) Living with others & $-0.06^{* *}$ & -0.04 & $-0.11^{* *}$ & -0.07 & $-0.10^{*}$ \\
\hline Constant & $1.50^{* * *}$ & $0.63^{*}$ & $1.77^{* * *}$ & $1.06^{* * *}$ & $1.39^{* * * *}$ \\
\hline $\mathrm{N}$ & 2087 & 899 & 1188 & 1182 & 905 \\
\hline Adjusted R2 & 0.08 & 0.02 & 0.08 & 0.06 & 0.05 \\
\hline
\end{tabular}

Source: see Table $1 .{ }^{*}<0.1,{ }^{* *}<0.05,{ }^{* * *}<0.01$.

As to other intergenerational variables, chatting with children/grandchildren significantly reduces the positive feelings of the elderly by 36\%; and its negative impact on male oldest-old's positive feelings is especially high (52\%). The more often the oldest-old chatted with their children, the less likely they had positive feelings. This finding seems to be contradictory to our common sense. I will discussion my tentative explanation of this finding in the conclusion and discussion part.

Sharing thoughts with children, on the other hand, significantly reduces the first negative feeling index score by $40 \%$. Its impact on reducing female and rural oldest-old's negative feelings is even more considerable (59\% and $72 \%$, respectively). Sharing thoughts with children/grandchildren also decreases the second negative feeling index for females and rural elderly. Such results reveal that sharing thoughts with children and chatting with children meant differently to the Chinese oldest-old. People often share thoughts with those whom they trust and feel close to. In this case, if the Chinese oldest-old were willing to share thoughts with their children/grandchildren, it implies a close intergenerational relationship. Thus, I hypothesize that "sharing thoughts with children" is a much better indicator of intergenerational relations than "chatted with children frequently." The rest of the two measures of intergenerational relations do not show significant effects on either positive or negative feelings of the Chinese oldest-old.

Coefficients for most control variables are significant, suggesting that married, Han, well-educated and urban elderly along with those who were economically doing well and rated their health better tended to have better well-being than those who were not married, minority, poorly-educated, rural elderly as well as those with lower economic status and ADL disabilities. Meanwhile, those who lived with other family members tended to report more positive feelings than negative feelings.

Findings shown in Tables 2-4 clearly suggest that the Chinese oldest-old's subjective well-being is in part associated with differences in their intergenerational relations, even after controlling for the elderly's demographic features. Basically, financial support from offspring (or financial exchanges with offspring) only reduces their negative feelings, whereas non-financial support from offspring, such as sharing thoughts, promotes elderly's positive feelings and reduces their negative feelings. Variations by gender and residence are shown in the association between intergenerational relations elderly's subjective well-being.

\section{Conclusion and Discussion}

This research has examined how intergenerational relations influence the Chinese oldest-old's subjective wellbeing. In summary, the results corroborate previous findings that better intergenerational relations promote the 
elderly’s subjective well-being. The research also highlights some new evidence from analyzing the 2011 wave of the CLHLS dataset. To illustrate, financial exchanges with offspring or receiving financial support from children/grandchildren decrease negative feelings of the elderly; but such financial support and exchanges do not promote their positive feelings. Instead, sharing thoughts with children largely improves the elderly's subjective well-being by both promoting their positive feelings and reducing negative feelings. These findings have answered the question that I raised earlier in the article that for the Chinese oldest-old, non-financial forms of intergenerational relations may be more important factors influencing the Chinese elderly's subjective well-being.

The research finds that those who often chatted with children/grandchildren did not report better subjective well-being. I am not sure how to interpret this result as it is contradictory to common sense. One explanation could be that perhaps the oldest-old who often chatted with children had very small social networks or supporting circle, which deteriorated their well-being. As Zhang's (2015) research showed, larger social networks significantly lowered the likelihood of elderly living with other family members. For those who often chatted with children could be the individuals with little communication and interaction with others; they therefore showed worse well-being. Chen and Chen (2012)'s study demonstrated that elderly engaging in various degrees of social interaction with others and the environment led to different levels of emotional dependence and perceived social support. Thus, it is reasonable for one to argue that often talking to children/grandchildren may indicate relatively restricted social networks, which has negative impact on elderly's subjective well-being. Of course the explanation remains as a hypothesis until it is formally tested.

Variations among subgroups are also shown when studying intergenerational relations and elderly's subjective well-being. Specifically, receiving financial support from children decreased female elderly's negative feelings to a greater extent than any other subgroups (males, rural and urban seniors). In contrast, receiving financial support from children considerably increased negative feelings of male elderly. Sharing thoughts with children reduced negative feelings of females and rural seniors to a greater extent than their male and urban counterparts. Chatting with children more often also damaged male elderly’s well-being most significantly as compared to other subgroups. These findings imply that females and rural residents are more similar than different when it comes to the ways in which intergenerational relations affect elderly's subjective well-being. For female and rural seniors, both financial and emotional support can promote their subjective well-being. Male seniors are different. Sharing thoughts with children did not significantly reduce their negative feelings, whereas financially dependent on their adult children considerably increased their negative feelings. Thus, for male elderly, financial independence perhaps means autonomy, which is directly linked to their well-being. The gender differences along with the differentiation by residence draw future research attention to distinguishing the elderly groups when conducting aging analyses. The unique features of male elderly also suggest future research to explore factors (such as instrumental and tangible support factors) besides financial and emotional support factors to investigate the influence of intergenerational relations on male oldest-old's subjective well-being. These findings have answered the first two research questions that I raised earlier in the article that there are significant differences by gender and residence when intergenerational relations influence the elderly's subjective well-being.

Besides intergenerational relations, the research also showed that marriage, higher socioeconomic status, urban residency and better health status improved elderly's subjective well-being. A more disadvantaged socioeconomic position, worse health situation and rural residence are found to be more likely to decrease the elderly's well-being. These findings suggest that the socioeconomically more disadvantaged individuals should perhaps be the focus of future research on promoting elderly's well-being.

A limitation of the research is that when studying intergenerational relations, the current analysis has not included enough intergenerational exchange variables to operationalize intergenerational relations. The only intergenerational exchange variable applied in the analysis is the financial exchange variable. Prior research has emphasized that intergenerational exchanges between elderly and their adult children can promote the elderly’s psychological well-being (Davey \& Eggebeen, 1998; Waite, 2009). The intergenerational exchange variables applied in this research, financial exchange variables, only showed significant effect on decreasing the elderly parents' negative well-being but not increasing positive well-being. Of course, financial exchanges between elderly parents and adult children can be reflected in many ways, such as paying for housing loans, giving money for special occasions, running errands, sharing intergenerational housing, etc. (Attias-Donfut, Ogg \& Wolff, 2005; Litwin, 2004). Researchers argued that studying intergenerational financial exchanges also required considering not only the form of exchange but also the extent and purpose of exchanges (Merz et al., 2009). This current research has not taken these dimensions into consideration. 
Besides financial exchanges, other important dimensions of intergenerational exchanges, such as grandparents taking care of grandchildren, have not been examined in this analysis. This is because the CLHLS dataset does not have specific measures of intergenerational exchanges. Previous studies have showed significant effects of various forms of intergenerational exchanges on elderly's well-being (Baker \& Silverstein, 2008; Blustein, Chan, \& Guanais, 2004; Hughes et al., 2007). Future research may extend this current research by applying more measures of intergenerational exchanges to conduct analyses on intergenerational relations and the Chinese elderly's well-being.

\section{Funding}

The research is funded by Social Science Research Grant of China Bureau of Education (Project ID: 15YJC 840047) and Program for Young Innovative Research Team in China University of Political Science and Law.

\section{Note}

Data used for this research were provided by the Chinese Longitudinal Healthy Longevity Survey (CLHLS), managed by the Center for Healthy Aging and Family Studies, Peking University. This survey is supported in part by funds from Duke University under an award from the US National Institutes of Aging and by the matching support of Chinese institutions.

\section{References}

Attias-Donfut, C., Ogg, J., \& Wolff, F. C. (2005). European Patterns of Intergenerational Financial and Time Transfers. European Journal of Aging, 2, 161-173. http://dx.doi.org/10.1007/s10433-005-0008-7

Baker, L.A., \& Silverstein, M. (2008). Depressive Symptoms among Grandparents Raising Grandchildren: The Impact of Participation in Multiple Roles. Journal of Intergenerational Relationships, 6, 285-304. http://dx.doi.org/10.1080/15350770802157802

Blustein, J, Chan, S., \& Guanais, F. C. (2004). Elevated Depressive Symptoms among Caregiving Grandparents. Health Service Research, 39, 1671-1689. http://dx.doi.org/10.1111/j.1475-6773.2004.00312.x

Carpenter, B. D. (2001). Attachment Bonds between Adult Daughters and Their Older Mothers: Associations with Contemporary Caregiving. Journal of Gerontology: Psychological Sciences, 56B, 257-266. http://dx.doi.org/10.1093/geronb/56.5.P257

Chen, F. N., \& Short, S. E. (2008). Household Context and Subjective Well-Being among the Oldest Old in China. Journal of Family Issues, 29, 1379-1403. http://dx.doi.org/10.1177/0192513X07313602

Chen, Y.-J., \& Chen, C.-Y. (2012). Living Arrangement Preferences of Elderly People in Taiwan as Affected by Family Resources and Social Participation. Journal of Family History, 37, 381-394. http://dx.doi.org/10.1177/0363199012440948

Cicirelli, V. G. (1993). Attachment and Obligation as Daughters' Motives for Caregiving Behavior and Subsequent Effect on Subjective Burden. Psychology and Aging, 8, 144-155. http://dx.doi.org/10.1037/0882-7974.8.2.144

Cronbach, L. J. (1951). Coefficient Alpha and the Internal Structure of Tests. Psychometrika, 16, 151-160. http://dx.doi.org/10.1007/BF02310555

Davey, A., \& Eggebeen, D. (1998). Patterns of Intergenerational Exchange and Mental Health. Journal of Gerontology: Psychological sciences, 53B, 86-95. http://dx.doi.org/10.1093/geronb/53B.2.P86

Deng Yunlong, Yang Zhonghua, \& Chen Xiangyi 邓云龙, 阳中华，陈向一 (2012). Shehui Zhichi he Jiating Gongneng Yu Laonianren Zhuguan Xingfugande Xiangguanxing. 社会支持和家庭功能与老年人主观幸福感的相关性 [The Association between Social Support, Family Function and the Elderly’s Subjective Well-Being]. Zhongguo Laonianxue Zaizhi 中 国老年学杂志, 32, 3501-3503.

Hughes, M. E., Waite, L. J., La Pierre, T. A., \& Luo, Y. (2007). All in the Family: The Impact of Caring for Grandchildren on Grandparents' Health. The Journal of Gerontology Series B: Psychological Science and Social Science, 62, S108-S119. http://dx.doi.org/10.1093/geronb/62.2.S108

Ikking, K. K., van Tilburg, T., \& Knipscheer, K. (1999). Perceived Instrumental Support Exchanges in Relationships between Elderly Parents and Their Adult Children: Normative and Structural Explanations. Journal of Marriage and the Family, 61, 831-844. http://dx.doi.org/10.2307/354006

Levitt, M. J., Guacci, N., \& Weber, R. A. (1992). Intergenerational Support, Relationship Quality, and Well-Being: A Bicultural Analysis. Journal of Family Issues, 13, 465-481. http://dx.doi.org/10.1177/019251392013004005

Litwin, H. (2004). Intergenerational Exchange Patterns and Their Correlates in an Aging Israeli Cohort. Research on Aging, 26, 202-223. http://dx.doi.org/10.1177/0164027503260631 
Merz, E.-M., Consedine, N. S., Schulze, H.-J., \& Schuengel, C. (2009). Wellbeing of Adult Children and Ageing Parents: Associations with Intergenerational Support and Relationship Quality. Ageing and Society, 29, 783-802. http://dx.doi.org/10.1017/S0144686X09008514

Roberts, R. E., \& Bengtson, V. L. (1990). Is intergenerational Solidarity a Unidimensional Construct? A Second Test of a Formal Model. Journal of Gerontology: Psychological Science, 45, 12-20. http://dx.doi.org/10.1093/geronj/45.1.S12

Shen Jiliang, Zhou Liqing, Tong Yan, \& Zhang Jinying 申继亮, 周丽清, 佟雁, 张金颖 (2003). Qinzi Zhichi he Xiaoshun Qidai dui Laonianren Gudugan de Yingxiang 亲子支持和孝顺期待对老年人孤独感的影响 [The Impact of Intergenerational Social Support and Filial Expectation on Loneliness of Elderly Parents]. Zhongguo Linchuang Xinlixue Zazhi 中国 临床心理学杂志, 11, 167-169.

Zhang Wenjuan, \& Li Shuzhuo 张文娟, 李树茁 (2004). Daiji Zhichi dui Gaoling Laoren Shenxin Jiankang Zhuangkuang de Yingxiang Yanjiu. 代际支持对高龄老人身心健康状况的影响研究 [The Impact of Intergenerational Support on Chinese Oldest-Old’s Physical and Mental Health]. ZhongguoRenkouKexue 中国人口学刊, Zengkan, 37-42.

Silverstein, M., Parrott, T. M., \& Bengtson, V. L. (1995). Factors that Predispose Middle-Aged Sons and Daughters to Provide Social Support to Older Parents. Journal of Marriage and the Family, 57, 465-475. http://dx.doi.org/10.2307/353699

Silverstein, M., Chen, X., \& Heller, K. (1996). Too Much of a Good Thing? Intergenerational Social Support and the Psychological Well-Being of Older Parents. Journal of Marriage and the Family, 58, 970-982. http://dx.doi.org/10.2307/353984

Umberson, D. (1992). Relationships between Adult Children and Their Parents: Psychological Consequences for Both Generations. Journal of Marriage and the Family, 54, 3, 664-74. http://dx.doi.org/10.2307/353252

Waite, C. (2009). Building on Strengths: Intergenerational Practice with African American families. Social Work, 54, 278287. http://dx.doi.org/10.1093/sw/54.3.278

Whitbeck, L. B., Hoyt, D. R., \& Tyler, K. A. (2001). Family Relationship Histories, Intergenerational Relationship Quality, and Depressive Affect among Rural Elderly People. Journal of Applied Gerontology, 20, 214-229. http://dx.doi.org/10.1177/073346480102000206

Zhang, L. (2015). Determinants of Living Arrangements among the Chinese Elderly: New Evidence from the CLHLS 2011Wave. Chinese Studies, 4, 32-43. http://dx.doi.org/10.4236/chnstd.2015.41006

\begin{tabular}{|c|c|c|}
\hline Variables & Individual Items & Alpha Values \\
\hline \multirow[t]{3}{*}{ Positive feelings } & Q1: How do you rate your life at present? & 0.51 \\
\hline & Q2: Do you always look on the bright side of things? & \\
\hline & Q3: Do you feel happy as younger? & \\
\hline \multirow[t]{3}{*}{ Negative feelings I } & Q4: Do you feel fearful or anxious? & 0.63 \\
\hline & Q5: Do you feel lonely and isolated? & \\
\hline & Q6: Do you feel useless as age? & \\
\hline \multirow[t]{2}{*}{ Negative feelings II } & Q7: Have you felt sad, blue, or depressed for two weeks or more in last 12 months? & 0.72 \\
\hline & Q8: Have you lost interest in most things like hobbies, work, or similar activities? & \\
\hline
\end{tabular}

